\title{
The importance of community consultation and social support in adhering to an obesity reduction program: results from the Healthy Weights Initiative
}

\author{
This article was published in the following Dove Press journal: \\ Patient Preference and Adherence \\ 15 October 2015 \\ Number of times this article has been viewed
}

\author{
Mark Lemstra' \\ Marla R Rogers ${ }^{2}$ \\ 'Alliance Wellness and Rehabilitation, \\ Moose Jaw, ${ }^{2}$ College of Medicine, \\ University of Saskatchewan, \\ Saskatoon, SK, Canada
}

Background: Few community-based obesity reduction programs have been evaluated. After 153 community consultations, the City of Moose Jaw, SK, Canada, decided to initiate a free comprehensive program. The initiative included 71 letters of support from the Mayor, every family physician, cardiologist, and internist in the city, and every relevant community group including the Heart and Stroke Foundation, the Canadian Cancer Society, and the Public Health Agency of Canada.

Objective: To promote strong adherence while positively influencing a wide range of physical and mental health variables measured through objective assessment or validated surveys.

Methods: The only inclusion criterion was that the individuals must be obese adults (body mass index $>30 \mathrm{~kg} / \mathrm{m}^{2}$ ). Participants were requested to sign up with a "buddy" who was also obese and identify three family members or friends to sign a social support contract. During the initial 12 weeks, each individual received 60 group exercise sessions, 12 group cognitive behavioral therapy sessions, and 12 group dietary sessions with licensed professionals. During the second 12-week period, maintenance therapy included 12 group exercise sessions ( 24 weeks in total). Results: To date, 243 people have been referred with 229 starting. Among those who started, 183 completed the program (79.9\%), while 15 quit for medical reasons and 31 quit for personal reasons. Mean objective reductions included the following: $31.0 \mathrm{lbs}$ of body fat, 3.9\% body fat, 2.9 in from the waist, 2.3 in from the hip, blood cholesterol by $0.5 \mathrm{mmol} / \mathrm{L}$, systolic blood pressure by $5.9 \mathrm{mmHg}$, and diastolic blood pressure by $3.2 \mathrm{mmHg}$ (all $P<0.000$ ). There were no changes in blood sugar levels. There was also statistically significant differences in aerobic fitness, self-report health, quality of life measured by Short Form-36, and depressed mood measured by Beck Depression Inventory-II (all $P<0.000$ ). Independent risk factors for not completing the program were not having a family member or friend sign a social support contract (odds ratio 2.91, 95\% confidence interval $1.01-8.34, P=0.047$ ) and lower education (odds ratio 2.90, 95\% confidence interval 1.20-7.03, $P=0.018$ ).

Conclusion: Comprehensive obesity reduction programs can be effective when there is extensive consultation at the community level and social support at the individual level.

Keywords: community based, obesity, social support, program adherence

\section{Introduction}

The rising prevalence of obesity is a concern in Canada. The overall prevalence of obesity (defined as a body mass index [BMI] of $30 \mathrm{~kg} / \mathrm{m}^{2}$ or more) increased from $6.1 \%$ of Canadian adults in 1985 to $18.3 \%$ in $2011 .{ }^{1}$ In 2011 , the Ministry of Health of Saskatchewan, Canada, released a report concluding that $60 \%$ of adults aged $20-64$ years were either overweight or obese. ${ }^{2}$
Alliance Wellness and Rehabilitation, B70 500-I st Avenue North West, Moose Jaw, SK, Canada

$\mathrm{Tel}+\mathrm{I} 3062303911$

$\mathrm{Fax}+\mathrm{I} 3066936202$

Email marklemstra@shaw.ca 
The health implications of obesity have been well documented including increased risk of premature mortality, ${ }^{3-9}$ cardiovascular disease, ${ }^{10,11}$ diabetes, ${ }^{12}$ and some cancers. ${ }^{13-15}$ Additionally, the condition is associated with a number of health concerns among children and adolescents, including depression and anxiety, ${ }^{16}$ migraines, ${ }^{17,18}$ and sleep-disordered breathing. ${ }^{19}$ Increased rates of obesity can be attributed to a complex mix of environmental, socioeconomic, activityrelated, and dietary factors. ${ }^{20-25}$

A systematic review of effective individual strategies to treat obesity in adults concluded that there are a number of ways to reduce weight. ${ }^{26}$ For nutrition, the primary factor is consuming a low-calorie diet. ${ }^{26-28}$ For activity, aerobic exercise is more effective for weight loss than anaerobic exercise. Aerobic exercise should be performed for up to 60 minutes at a time, up to $80 \%$ maximal heart rate, and 5 days per week. ${ }^{29-32}$ Cognitive behavioral therapy (CBT) is also an effective strategy used for weight loss, especially when in combination with diet and exercise. ${ }^{26} \mathrm{CBT}$ is useful to promote adherence to dietary and exercise recommendations. In addition to these methods, a person also requires significant social support in order to make complex behavioral changes, ${ }^{33}$ and has been found to have a positive effect on achieving weight loss, weight loss program completion, and weight loss maintenance. ${ }^{34,35}$

Community-based interventions to reduce obesity and promote weight loss have been reported across North America, but unfortunately, few have been evaluated rigorously. Of the interventions that have been evaluated, very few have been found to be effective. As such, the International Obesity Task Force (IOTF) released ten guidelines for community-based obesity reduction programs. These ten principles include the following: 1) Education alone is not sufficient to change weight-related behaviors. Environmental and societal interventions are also required to promote and support behavior change. 2) Action must be taken to integrate physical activity into daily life, not just to increase leisure time. 3) Sustainability of programs is crucial to enable positive change in diet, activity, and obesity levels over time. 4) Political support, intersectional collaboration, and community participation are essential for success. 5) Acting locally allows programs to be tailored to meet needs, expectations, and opportunities. 6) All parts of the community must be reached - not just the motivated healthy. 7) Programs must be adequately resourced. 8) Where appropriate, programs should be integrated into existing initiatives and facilities. 9) Programs should build on existing evidence. 10) Programs should be properly monitored, evaluated, and documented in order to allow for dissemination and transfer of experience to other communities. ${ }^{20}$
The Healthy Weights Initiative (HWI) was launched in Moose Jaw, SK, Canada, in January of 2014. After 153 community consultations, a free, comprehensive, multidisciplinary program was agreed upon with letters of support from all relevant medical and service provider groups of the community. The program was designed to follow evidence-based recommendations for communities outlined by the IOTF and evidence-based strategies for individuals to promote longterm obesity reduction. ${ }^{20,26}$ These interventions were coupled with CBT and significant social support to promote adherence and program completion. The objectives of this paper are to report adherence to the program, and physical and mental health outcomes to date, and to identify independent risk indicators for not completing the program.

\section{Methods}

\section{Setting}

Moose Jaw, SK, Canada, is a city with a population of 33,274 . The city has a prevalence of adult obesity of $26.3 \%$ or $\sim 5,000$ adults. $^{36}$

\section{Ethics}

The study meets the requirements for exemption status per Article 2.5 of the Tri-Council Policy Statement: Ethical Conduct for Research Involving Humans, December 2014. As such, ethics exemption was obtained from the Behavioural Research Ethics Board from the University of Saskatchewan, Canada (BEH-15-28).

\section{Participants}

Eligible participants were obese (as defined as a BMI of $\geq 30 \mathrm{~kg} / \mathrm{m}^{2}$ ) adults who were referred by a medical doctor. All adults received a medical screen by their own physician to ensure that they could safely participate. No other inclusion or exclusion criteria were applied. Data collection was encouraged by participants, but it was not mandatory in order to complete the program. All post-program data provided by the participants were volunteered.

\section{Measures}

During their medical screen, participants also had their blood pressure, blood sugar, and blood cholesterol levels tested. Each participant also received an individual fitness evaluation which included a calculation of BMI, waist-to-hip ratio, body fat percentage, and aerobic fitness. ${ }^{37}$

General health status was measured using the Short Form-36 (SF-36). ${ }^{38}$ The SF-36 measures eight dimensions of health, including physical functioning, physical role functioning, 
bodily pain, general health perceptions, vitality, social role functioning, emotional role functioning, and mental health.

Depressed mood was measured using the Beck Depression Inventory-II. ${ }^{39}$ This tool has a good internal scale reliability for community-dwelling adults (Cronbach's alpha $=0.86-0.92) .{ }^{40}$

Barriers to physical activity were measured with 15 questions from the Canadian Fitness and Lifestyle Research Institute's Physical Activity Monitor. ${ }^{41}$ Aerobic fitness score was obtained from using the Modified Canadian Aerobic Fitness Test results, combined with participants' weight and age. ${ }^{42}$

\section{Community support}

Prior to implementation, every family doctor, cardiologist, and internist in the city, along with the health region's medical health officer, provided written letters of support. Letters of support were also obtained from the Mayor, the Regional Inter-sectoral Committee (all regional government leaders), the Healthy Active Living Committee, the In Motion Committee, the Young Men's Christian Association (YMCA), and the Heart and Stroke Foundation. Once the program started, letters of support were also obtained from the local federal Member of Parliament, both provincial Members of the Legislative Assembly, the Chief of Police, the largest grocery store (the Co-op), the largest bank (the Credit Union), the largest private employer (Thunder Creek Pork), the largest public employer (the City of Moose Jaw), the Canadian Cancer Society, and the Public Health Agency of Canada.

\section{Procedures}

In order to meet all ten recommendations of the IOTF, the program included more comprehensive intervention than education alone. Supervised physical activity along with significant social support ensured that behavioral change was adopted into daily life. The group management and relatively low-cost intervention ensured long-term sustainability. Political support was provided by the Mayor and other politicians. The intervention was based on 153 local community consultations prior to beginning. All parts of the community were reached, given that every doctor in the community agreed to participate along with every relevant community group. The program was adequately resourced through a local wellness facility and incorporated existing facilities through the local YMCA. The initiative was evidence based and included a thorough protocol and evaluation plan to ensure transferability to other cities. ${ }^{16}$

The program was free of charge to all participants. Group-based sessions were held at the local YMCA. Each participant received group-based programming for 12 consecutive weeks which included five group exercise sessions per week (60 in total) led by an exercise therapist, one group dietary session per week ( 12 in total) led by a dietician, and one group CBT session per week (12 in total) led by a registered psychologist. Upon completion of the initial 12 weeks, participants received group-based exercise therapy once per week for an additional 12 weeks for maintenance ( 24 weeks in total).

The exercise therapy sessions started with 20 minutes of aerobic exercise at 50\% maximal heart rate on either a treadmill or a bicycle. Once the participant progressed to 60 minutes per session, the second goal was to increase intensity to a maximum of $80 \%$ maximal heart rate.

The group dietary education sessions included the following: 1) Canada's food guide, 2) planning your grocery trip, 3) reading labels, 4) fats, 5) eating out, 6) carbohydrates, 7) guidelines for fluid intake, 8) fiber intake, 9) how to make your recipes healthier, 10) heart-healthy eating, 11) protein, and 12) review.

The group CBT education sessions included the following: 1) discussing family and friend social support contracts, 2) barriers, 3) motivation and connecting our thoughts and behaviors, 4) identifying automatic habits, 5) challenging automatic thoughts, 6) feelings and emotional eating/emotional hunger, 7) addressing emotional eating (hunger tolerance and distraction), 8) values and beliefs, 9) preparation and planning for success, 11) coping with setbacks, and 12) mindsets.

Each participant was asked to attend with a family member or friend who also had a BMI of at least $30 \mathrm{~kg} / \mathrm{m}^{2}$. This social support individual, or "buddy", was also asked to sign a social support contract, which acknowledges the participant's physical activity and dietary goals, possible barriers to achieving those goals, solutions to overcoming those barriers, and how the buddy can help implement those solutions. Three other family members or friends also signed the social support contract. Each of these components is recommended by the Canadian Society for Exercise Physiology Physical Activity Training for Health guidelines. ${ }^{37}$

At 24 weeks, identical outcome measures from baseline were obtained.

\section{Analysis}

Using SPSS 22.0, mean scores of each outcome were compared before and after the program using paired sample $t$-tests $(P<0.05)$. Mean adherence was calculated using attendance data for exercise, nutrition, and CBT sessions.

Cross-tabulations were performed between the variable of program completion and demographic variables, the presence 
of one or more comorbidities, depressed mood, "buddy" participation, completed social support contract, self-report health, self-report mental health, and barriers to physical activity. After these initial cross-tabulations, binary logistic regression was used to determine the independent association between the outcome variable of not completing the program and the potential explanatory variables. The unadjusted effect of each covariate was determined and then entered one step at a time based on changes in the $-2 \log$ likelihood and the Wald test. The final results are presented as adjusted odds ratios (ORs) with 95\% confidence intervals (CIs). ${ }^{43}$

\section{Results}

From January 2014 to March 2015, 243 people were referred to the program, with 229 starting (94.2\%). Among those who started, 183 completed the program (79.9\%), while 15 quit for medical reasons (ie, scheduled surgery unrelated to obesity) and 31 quit for personal reasons. Among those who completed the 24-week program, mean adherence for the exercise sessions, dietary sessions, and CBT sessions was $81 \%, 71 \%$, and $68 \%$, respectively. Upon program completion, 1-year gym memberships were purchased by $71.7 \%$ of participants. Demographic results of the sample are presented in Table 1.

Prior to starting the program, the mean BMI of participants was $37.7 \mathrm{~kg} / \mathrm{m}^{2}\left(36.3 \mathrm{~kg} / \mathrm{m}^{2}\right.$ for males and $38.2 \mathrm{~kg} / \mathrm{m}^{2}$ for females). Mean reduction in BMI was $1.7 \mathrm{~kg} / \mathrm{m}^{2}(P<0.000)$ after the program. Participants lost an average of $31 \mathrm{lb}$ of body fat $(P<0.000)$, and reduced their body fat by $3.9 \%(P<0.000)$. Waist circumference was reduced by a mean of 2.9 in $(7.4 \mathrm{~cm})$ and hip circumference by 2.3 in or $5.8 \mathrm{~cm}(P<0.000)$. Pre- and post-means by sex are reported in Table 2 .

Prior to beginning the program, 29.5\% had hypertensive systolic blood pressure. After the program, this number was reduced to $8.1 \%$. There was a statistically significant reduction in diastolic blood pressure $(-2.3 \mathrm{mmHg})$ and systolic blood pressure $(-5.9 \mathrm{mmHg})$. Prior to the program, the mean blood cholesterol among participants was $5.0 \mathrm{mmol} / \mathrm{L}$, and this reduced to $4.5 \mathrm{mmol} / \mathrm{L}$ after the program $(P<0.000)$. Results of the sample are presented in Table 3.

At baseline, $71.1 \%$ had a poor aerobic fitness score. ${ }^{38}$ After program completion, the percent with a poor aerobic fitness score dropped to 45.7. Aerobic fitness scores increased from a mean of 199.7 to $271(P<0.000)$. There were also statistically significant improvements in selfreport health, self-report mental health, depressed mood scores (Table 3), and in all eight dimensions of the SF-36 (Table 4).
Table I Healthy Weight Initiative participant demographics

\begin{tabular}{ll}
\hline Demographics & Percent \\
\hline Sex & \\
Male & 25.9 \\
Female & 74.1 \\
Age category (years) & \\
I8-25 & 6.2 \\
$26-34$ & 17.7 \\
$25-44$ & 24.7 \\
45-54 & 23.0 \\
55-64 & 27.6 \\
Missing & 0.8 \\
Marital status & \\
Married & 61.7 \\
Common law & 10.3 \\
Single & 27.2 \\
Missing & 0.8 \\
Education level & \\
Less than high school & 7.8 \\
High school & 36.6 \\
College/technical/trade & 40.7 \\
University & 13.2 \\
Missing & 1.6 \\
Employment status & \\
Unemployed & 17.3 \\
Nonprofessional & 72.0 \\
Professional & 8.2 \\
Retired & 1.6 \\
Missing & 0.8 \\
At least one reported & \\
None reported & 69.5 \\
Missing & 27.6 \\
\hline Note: & 2.9 \\
\hline
\end{tabular}

Note: $\mathrm{N}=229$.

\section{Independent risk factors for non- completion}

After cross-tabulation, age, sex, marital status, and employment status were not significantly associated with not completing the program. Variables with unadjusted yet statistically significant associations are presented in Table 5. Only one barrier to physical activity (past negative experiences, $P=0.036)$ was initially associated with non-completion. Education level was associated with non-completion: $64.4 \%$ of those who did not complete postsecondary education did not complete the program compared to $15.6 \%$ of those with university education $(P=0.005)$. Higher education level was associated with higher ( $80 \%$ or more) gym session attendance $(P=0.007)$ but not with higher attendance in the diet or CBT sessions. Having a completed social support contract was significantly associated with higher CBT session attendance and diet session attendance (both $P=0.001$ ), but education level was not. Depressed mood was also initially significantly associated with non-completion, as $20.9 \%$ of 
Table 2 Healthy Weights Initiative change in weight and size

\begin{tabular}{|c|c|c|c|c|}
\hline Physical measures & Pre-mean (SD) & Post-mean (SD) & Change & Significance \\
\hline Weight (lbs) & $237.4(45.2)$ & $227.9(42.9)$ & -9.5 & 0.000 \\
\hline Male & $254.8(44.1)$ & $244.5(42.6)$ & -10.3 & \\
\hline Female & $230.9(44.0)$ & $221.9(41.5)$ & -9.0 & \\
\hline Body fat (lbs) & $103.4(31.8)$ & $72.4(43.5)$ & -31.0 & 0.000 \\
\hline Male & $96.1(36.3)$ & $69.2(40.1)$ & -26.9 & \\
\hline Female & $106.5(28.8)$ & $73.6(44.7)$ & -32.9 & \\
\hline Percent body fat & $44.8(5.1)$ & $40.9(5.3)$ & -3.9 & 0.000 \\
\hline Male & $39.0(5.0)$ & $34.9(5.0)$ & -4.1 & \\
\hline Female & $46.9(3.1)$ & $43.2(3.4)$ & -3.7 & \\
\hline BMI $\left(\mathrm{kg} / \mathrm{m}^{2}\right)$ & $37.7(6.6)$ & $36.0(6.2)$ & -1.7 & 0.000 \\
\hline Male & $36.3(5.9)$ & $34.8(5.9)$ & -1.5 & \\
\hline Female & $38.2(6.8)$ & $36.4(6.3)$ & -1.8 & \\
\hline Waist circumference (in) & $45.2(5.3)$ & $42.3(5.1)$ & -2.9 & 0.000 \\
\hline Male & $47.7(5.1)$ & $44.8(5.3)$ & -2.9 & \\
\hline Female & $44.2(5.1)$ & $4 I .4(4.7)$ & -2.8 & \\
\hline Hip circumference (in) & $50.6(6.0)$ & $48.3(5.6)$ & -2.3 & 0.000 \\
\hline Male & $48.2(5.1)$ & $45.8(4.9)$ & -2.4 & \\
\hline Female & $5 \mathrm{I} .4(6.1)$ & $49.2(5.6)$ & -2.2 & \\
\hline
\end{tabular}

Abbreviations: SD, standard deviation; BMI, body mass index.

those who did not complete the program had moderately or severely depressed mood, compared to $7.6 \%$ of those who did complete the program $(P=0.029)$.

After logistic regression analysis, not having a signed social support contract increased the risk of non-completion (OR 2.91, 95\% CI 1.01-8.34, $P=0.047$ ), as did lower education levels (OR 2.90, 95\% CI 1.20-7.03, $P=0.018$ ).

\section{Discussion}

The HWI included all ten principles of community-based obesity reduction set out by the IOTF, and as such, has shown positive results to date. The program targets those who are already obese, and is offered at no cost to participants. Over the 24 -week program, $79.9 \%$ of those who started the program completed it. Both male and female participants had significant reductions in BMI, body fat, weight, waist circumference, hip circumference, blood pressure, and blood cholesterol.

Maintaining overall adherence to the program was a key goal of the HWI. Regrettably, 20.1\% dropped out of the HWI. This is consistent with other weight loss programs. For example, a review of attrition in 13 different weight loss programs found non-completion rates ranging from $16 \%$ to $59 \% .{ }^{44}$ Maintaining overall adherence to the exercise, dietary, and CBT sessions was also a key goal of the HWI. Sixty-four percent of participants had high adherence to the exercise sessions. There was lower adherence for diet and CBT sessions, but due to these sessions being offered only once per week, missing 1 week reduced adherence by $8.3 \%$, while missing one exercise session reduced adherence by only $1.7 \%$. One-year follow-up is not yet complete. However, nearly three-quarters of participants purchased 1-year gym memberships.

Table 3 Healthy Weights Initiative - change is physical and mental health measures

\begin{tabular}{lllll}
\hline Physical and mental health measures & Pre-mean (SD) & Post-mean (SD) & Change & Significance \\
\hline Blood glucose (mmol/L) & $6.0(2.3)$ & $5.9(2.0)$ & -0.1 & $0.79 I$ \\
Blood cholesterol (mmol/L) & $5.0(I .1)$ & $4.5(I .2)$ & -0.5 & 0.000 \\
Diastolic blood pressure (mmHg) & $84.4(I I .2)$ & $81.2(8.8)$ & -3.2 & 0.000 \\
Systolic blood pressure (mmHg) & $131.5(I 3.0)$ & $125.6(8.3)$ & -5.9 & 0.000 \\
Average musculoskeletal pain & $3.6(2.5)$ & $2.7(2.0)$ & -0.9 & 0.000 \\
Aerobic quantitative fitness score & $199.7(106.7)$ & $271(88.2)$ & +71.3 & 0.000 \\
Self-report health (I-5) & $2.4(0.8)$ & $3.2(0.9)$ & +0.8 & 0.000 \\
Depression score & $10.2(7.1)$ & $4.9(4.5)$ & -5.3 & 0.000 \\
Self-report mental health (I-5) & $3.2(0.9)$ & $3.5(0.8)$ & +0.3 & 0.000 \\
\hline
\end{tabular}

Abbreviation: SD, standard deviation. 
Table 4 Healthy Weights Initiative - SF-36 dimensions

\begin{tabular}{lllll}
\hline Dimension & Pre-mean (SD) & Post-mean (SD) & Change & Significance \\
\hline Physical functioning & $71.6(21.3)$ & $86.1(17.4)$ & +14.5 & 0.000 \\
Role limitations due to physical health & $66.1(38.8)$ & $81.5(33.3)$ & +15.4 & 0.000 \\
Pain & $68.0(23.2)$ & $75.8(21.1)$ & +7.8 & 0.000 \\
General health & $54.0(22.6)$ & $68.8(19.6)$ & +14.8 & 0.000 \\
Vitality & $43.3(19.5)$ & $64.5(18.1)$ & +21.2 & 0.000 \\
Social functioning & $77.2(23.5)$ & $88.0(18.2)$ & +10.8 & 0.000 \\
Role limitations due to emotional health & $74.5(37.2)$ & $84.1(30.4)$ & +9.6 & 0.000 \\
Emotional well-being & $69.2(17.5)$ & $80.4(13.2)$ & +11.2 & 0.000 \\
\hline
\end{tabular}

Abbreviations: SF-36, Short Form-36; SD, standard deviation.

Not completing the program was initially associated with past negative experiences (barrier to exercise), depressed mood, low education levels, and not having a social support contract. After regression analysis, adjust risk indicators included not having a completed social support contract and having lower education levels.

\section{The importance of social support}

Having social support was an important factor for adherence in HWI and is supported in the literature. In a previous study, those who signed contracts experienced nearly double the weight loss of those participants who attempted to lose weight on their own. ${ }^{45}$ In another study of diabetic patients, those who signed contracts with their health care providers to achieve certain exercise and dietary behaviors recorded very high rates of program completion (90.9\%) to changing these habits. ${ }^{46}$ In a third study, participants with support versus a self-motivated approach for maintaining weight loss discovered that those who received social support were $37 \%$ more likely to maintain their weight loss over 2 years. ${ }^{47}$

In the HWI, social support is provided through social support contracts with a buddy and three family members or friends. This approach is supported by the literature. ${ }^{34,48,49}$ For example, a study to determine the benefits of social support for weight loss and maintenance recruited subjects to either participate alone or with three family members or friends. At 6-month follow-up, the study found participants who attended with family or friends were three times more likely to maintain their weight loss after program completion than those who attended alone. ${ }^{34}$

\section{Program completion and education level}

Many studies on weight loss programs do not look at the association between program adherence and education

Table 5 Significant associations with program completion of the Healthy Weights Initiative and independent risk indicators associated with non-completion

\begin{tabular}{|c|c|c|c|}
\hline Significantly associated variables & Completed (\%) & Not completed (\%) & $P$-value \\
\hline Education level & & & 0.005 \\
\hline High school or less & $7 I(4 I .0)$ & $29(64.4)$ & \\
\hline Postsecondary & $102(59.0)$ & $16(35.6)$ & \\
\hline Depressed mood & & & 0.029 \\
\hline Moderate/severe depressed mood & $13(7.6)$ & $9(20.9)$ & \\
\hline Mild depressed mood & $42(24.6)$ & $7(16.3)$ & \\
\hline No depressed mood & $116(67.8)$ & $27(62.8)$ & \\
\hline Buddy social support contract & & & 0.046 \\
\hline Buddy did not sign contract & $78(63.4)$ & $24(82.8)$ & \\
\hline Buddy signed contract & $45(36.6)$ & $5(17.2)$ & \\
\hline \multicolumn{4}{|l|}{ Barriers to exercise } \\
\hline Past negative experiences & & & 0.036 \\
\hline Very much a barrier & $15(15.3)$ & I (6.3) & \\
\hline Somewhat a barrier & $16(16.3)$ & $7(43.8)$ & \\
\hline Not really or at all a barrier & $67(68.4)$ & $8(50.0)$ & \\
\hline Independent variables & Odds ratio & $95 \%$ confidence interval & $P$-value \\
\hline High school or less than high school education level & 2.90 & $1.20-7.03$ & 0.018 \\
\hline Completed social support contract & 2.91 & $\mathrm{I} .0 \mathrm{I}-8.34$ & 0.047 \\
\hline
\end{tabular}

Note: Reference categories - postsecondary education and no social support contract. 
level. For example, in a systematic review of nonadherence in weight loss programs, only two of 13 included education level in the analysis. ${ }^{44}$ However, one study that did include education level in their risk analysis of nonadherence in a weight loss program for obese patients found that those with lower education were 3.26 times more likely to drop out of the program. ${ }^{50}$ The second study found lower education levels to be the largest predictor of weight loss program attrition. ${ }^{51}$ Some researchers have suggested that higher education may allow patients to be more able to understand information during the intervention. ${ }^{48}$ However, another study measured obesity-related knowledge among patients attending a weight management clinic and found the scores to be relatively low, despite the participants' attendance at the clinic for a mean of 18 months. $^{52}$

\section{Study limitations}

A limitation in this study is that 1-year results of the study are not yet available. It is possible that adherence, and therefore physical and mental health outcomes, will change.

\section{Conclusion}

In order to achieve significant weight loss in the long term, it is important to follow evidence-based recommendations. The HWI is a free, community-based obesity reduction program that addresses key physical activity and dietary behaviors along with CBT and significant social support. The program will continue to accept participants and will be evaluated with 1-year follow-up while being adopted in other cities in Saskatchewan.

\section{Acknowledgments}

The authors specially thank Alliance Wellness \& Rehabilitation and the Moose Jaw YMCA for administering the program and collecting data.

\section{Disclosure}

The authors report no conflicts of interest in this work.

\section{References}

1. Twells LK, Gregiry DM, Reddigan J, Midozi WK. Current and predicted prevalence of obesity in Canada: a trend analysis. Can Med Assoc J. 2014;2(35):18-26.

2. Chad K, Muhajarine N, Baxter-Jones A, et al. An overview of healthy weights in Saskatchewan. Univ Saskatchewan. 2011;1(1):1-45.

3. Van Dam RM, Li T, Spiegelman D, Franco OH, Hu FB. Combined impact of lifestyle factors on mortality: prospective cohort study in US women. BMJ. 2008;337:a1440.

4. Adams KF, Schatzkin A, Harris TB, et al. Overweight, obesity and mortality in a large prospective cohort of persons 50 to 71 years old. N Engl J Med. 2006;255(8):763-778.
5. Calle EE, Thun MJ, Petrelli JM, Rodriguez C, Heath CW Jr. Body mass index and mortality in a prospective cohort of US adults. $N$ Engl J Med. 1999;341(15):1097-1105.

6. Flegal KM, Graubard BI, Wiliamson DF, Gail MH. Excess deaths associated with underweight, overweight and obesity. JAMA. 2005;293(15): 1861-1867.

7. Fontaine KR, Redden DT, Wang C, Westfall AO, Allison DB. Years of life lost due to obesity. JAMA. 2003;289(2):187-193.

8. Olshansky SJ, Passaro DJ, Hershow RC, et al. A potential decline in life expectancy in the United States in the 21st century. N Engl J Med. 2010;170(15):1293-1301.

9. Jacobs EJ, Newton CC, Wang Y, et al. Waist circumference and allcause mortality in a large US cohort. Arch Intern Med. 2010;170(15): 1293-1301.

10. Manson JE, Stampfer MJ, Colditz GA. A prospective study of obesity and risk of coronary heart disease in women. N Engl J Med. 1990; 322(13):882-889.

11. De Koning L, Merchant AT, Pogue J, Anand SS. Waist circumference and waist-to-hip ratio as predictors of cardiovascular events: metaregression analysis of prospective studies. Eur Heart J. 2007;28(7): $850-856$.

12. Anderson JW, Kendall CWC, Jenkins DJA. Importance of weight management in type 2 diabetes: review with meta-analysis of clinical studies. J Am Coll Nutr. 2003;22(5):331.

13. Calle EE, Rodriguez C, Walker-Thurmond K, Thun MJ. Overweight, obesity, and mortality from cancer in a prospectively studied cohort of U.S. adults. $N$ Engl J Med. 2003;348(17):1625-1638.

14. Ligibel JA, Alfano CM, Courneya KS, et al. American society of clinical oncology position statement on obesity and cancer. J Clin Oncol. 2014;32(31):3568-3574.

15. Reeves GK, Pirie K, Beral V, et al; Million Women Study Collaboration. Cancer incidence and mortality in relation to body mass index in the Million Women Study: cohort study. BMJ. 2007;335(7630):1134.

16. Esposito M, Gallai B, Roccella M, et al. Anxiety and depression levels in prepubertal obese children: a case-control study. Neuropsychiatr Dis Treat. 2014;10:1897-1902.

17. Verrotti A, Carotenuto M, Altieri L, et al. Migraine and obesity: metabolic parameters and response to weight loss programme. Pediatr Obes. 2015;10(3):220-225.

18. Verrotti A, Agostinelli S, D'Egidio C, et al. Impact of weight loss program on migraine in obese adolescents. Eur J Neurol. 2013;2:394-397.

19. Carotenuto M, Bruni O, Santoro N, Del Giudice EM, Perrone L, Pascotto A. Waist circumference predicts the occurrence of sleepdisordered breathing in obese children and adolescents: a questionnairebased study. Sleep Med. 2006;7(4):357-361.

20. Kumanyika S, Jeffery RW, Morabia A, Ritenbaug C, Antipatis VJ. Public Health Approaches to the Prevention of Obesity (PAHPO) Working Group of the International Obesity Task Force (IOTF). Int $J$ Obes. 2002;26:425-436.

21. Tremblay MS, Willms JD. Is the Canadian childhood obesity epidemic related to physical inactivity? Int J Obes. 2003;27:1100-1105.

22. Crespo CJ, Smit E, Troiano RP, Bartlett SJ, Macera CA, Andersen RE. Television watching, energy intake, and obesity in US children. Arch Pediatr Adolesc Med. 2001;155:360-365.

23. Janssen I, Katzmarzyk PT, Boyce WF, King MA, Pickett W. Overweight and obesity in Canadian adolescents and their associations with dietary habits and physical activity patterns. $J$ Adolesc Health. 2004;35:360-367.

24. Mozaffarian D, Hao T, Rimm EB, Willett WC, Hu FB. Changes in diet and lifestyle and long-term weight gain in women and men. $N$ Engl $J$ Med. 2011;364:2392-2404.

25. Chang VW, Lauderdale DS. Income disparities in body mass index and obesity in the United States, 1971-2002. Arch Intern Med. 2005;165: 2122-2128.

26. Laddu D, Dow C, Hingle M, Thomson C, Going S. A review of evidence-based strategies to treat obesity in adults. Nutr Clin Pract. 2011;26(5):512-525. 
27. Romaguera D, Norat T, Mouw T, et al. Adherence to the Mediterranean diet is associated with lower abdominal adiposity in European men and women. J Nutr. 2009;139(9):1728-1737.

28. Panagiotakos DB, Chrysohoou C, Pitsavos C, Stefanadis C. Association between the prevalence of obesity and adherence to the Mediterranean diet: the ATTICA study. Nutrition. 2006;22(5):449-456.

29. Howley E, Franks B. Health Fitness Instructor's Handbook. 4th ed. Champaign, IL: Human Kinetics; 2003.

30. Willis LH, Slentz CA, Bateman LA, et al. Effects of aerobic and/or resistance training on body mass and fat mass in overweight or obese adults. J Appl Physiol. 2012;113(12):1831-1837.

31. Garber CE, Blissmer B, Deschenes MR, et al; American College of Sports Medicine. American College of Sports Medicine position stand. Quantity and quality of exercise for developing and maintaining cardiorespiratory, musculoskeletal, and neuromotor fitness in appsarently healthy adults: guidance for prescribing exercise. Med Sci Sports Exerc. 2011;43(7):1334-1359.

32. Willis FB, Smith FM, Willis AP. Frequency of exercise for body fat loss: a controlled, cohort study. J Strength Cond Res. 2009;23(8): 2377-2380

33. Christakis NA, Fowler JH. The collective dynamics of smoking in large social network. N Engl J Med. 2008;358(21):2249-2258.

34. Wing RR, Jeffery RW. Benefits of recruiting participants with friends and increasing social support for weight loss and maintenance. J Consult Clin Psychol. 1999;67(1):132-138.

35. Murphy JK, Willimson DA, Buzton AE, Moody SC, Absher N, Warner M. The long-term effects of spouse involvement upon weight loss and maintenance. Behav Ther. 1982;13(5):681-693.

36. Statistics Canada [Online]. Canadian Community Health Survey. Statistics Canada; 2013. Available from: www12.statcan.gc.ca. Accessed Dec 10, 2014.

37. Canadian Society for Exercise Physiology. Physical Activity Training for Health - Resource Manual. Ottawa, ON: Canadian Society for Exercise Physiology; 2013.

38. Ware JE, Kosinski M, Keller SD. SF-36 Physical and Mental Health Summary Scales: A Users' Manual. Boston, MA: The Health Institute; 1994.

39. Beck AT, Steer RA, Brown GK. Manual for the Beck Depression Inventory-II. San Antonio, TX: Psychological Corporation; 1996.
40. Segal DL, Coolidge FL, Cahill BS, O’Riley AA. Psychometric properties of the Beck Depression Inventory-II (BDI-II) among communitydwelling older adults. Behav Modif. 2008;32(1):3-20.

41. Canadian Fitness and Lifestyle Research Institute. Physical Activity Monitor. Ottawa, ON: Canadian Fitness and Lifestyle Research Institute; 1995.

42. Canadian Society for Exercise Physiology. The Canadian Physical Activity, Fitness, and Lifestyle Approach (CMAFLA). 3rd ed. Ottawa, ON: Canadian Society for Exercise Physiology; 2003.

43. Rothman KJ, Greenland S. Modern Epidemiology. 2nd ed. Philadelphia, PA: Lippincott Williams \& Wilkins; 1998.

44. Davis MJ, Addis ME. Predictors of attrition from behavioral medicine treatments. Ann Behav Med. 1999;21:339-349.

45. Harris MB, Bruner CG. A comparison of a self-control and a contract procedure for weight control. Behav Res Ther. 1971;9(4):347-354.

46. Schlenk FA, Boehm S. Behaviours in type II diabetes during contingency contracting. Appl Nurs Res. 1998;11(2):77-83.

47. Brantley PJ, Stewart DW, Myers VH, et al. Psychosocial predictors of weight regain in the weight loss maintenance trial. J Behav Med. 2014; 37(6):1155-1168.

48. Abildso CG, Zizzi S, Fitzpatrick SJ. Predictors of clinically significant weight loss and participant retention in an insurance-sponsored, community-based weight management program. Health Promot Pract. 2013;14(4):580-588.

49. Murphy JK, Williamson DA, Buxton AE, Moody SC, Absher N, Warner M. The long-term effects of spouse involvement upon weight loss and maintenance. Behav Ther. 1982;13(5):681-693.

50. Hadziabdic MO, Mucalo I, Hrabac P, Matic T, Rahelic D, Bozikov V. Factors predictive of drop-out and weight loss success in weight management of obese patients. J Hum Nutr Diet. 2014;28(supp12):24-32.

51. Elfhag K, Rossner S. Initial weight loss is the best predictor for success in obesity treatment and sociodemographic liabilities increase risk for drop-out. Patient Educ Couns. 2010;79(3):361-366.

52. Swift JA, Glazebrook C, Anness A, Goddard R. Obesity-related knowledge and beliefs in obese adults attending a specialist weightmanagement service: implications for weight loss over 1 year. Patient Educ Couns. 2009;74(1):70-76.
Patient Preference and Adherence

\section{Publish your work in this journal}

Patient Preference and Adherence is an international, peer-reviewed, open access journal that focuses on the growing importance of patient preference and adherence throughout the therapeutic continuum. Patient satisfaction, acceptability, quality of life, compliance, persistence and their role in developing new therapeutic modalities and compounds to optimize

\section{Dovepress}

clinical outcomes for existing disease states are major areas of interest for the journal. This journal has been accepted for indexing on PubMed Central. The manuscript management system is completely online and includes a very quick and fair peer-review system, which is all easy to use. Visit http://www dovepress.com/testimonials.php to read real quotes from published authors. 